\title{
Patients with tuberculosis in Bolivia: why do they die?
}

\author{
Jaime E. Ollé-Goig ${ }^{1}$
}

ABSTRACT The objective of this research was to analyze why patients with tuberculosis (TB) die and to evaluate whether there are factors contributing to their fatal outcome that could be corrected. A cross-sectional observational study was conducted of the patients with active TB or its sequelae admitted to the TB ward of the main public hospital in the city of Santa Cruz, Bolivia, over a 29-month period, from October 1993 through February 1996. The available records of the patients who died during hospitalization were reviewed. Out of 597 patients, 94 of them (15.7\%) died. We examined the records of 90 of these 94 patients. Their mean age was 35.1 years (standard deviation, 16.7 years), and 45 of the patients (50.0\%) were male. On admission 42 of the 90 patients $(46.7 \%)$ had never been treated for TB or had received anti-TB treatment for less than one month, $23(25.6 \%)$ had returned after having abandoned their TB treatment, $8(8.9 \%)$ had had an erroneous diagnosis, $6(6.7 \%)$ had tuberculosis sequelae, 6 $(6.7 \%)$ were undergoing tuberculosis treatment, and $5(5.6 \%)$ were known to have multidrugresistant TB. Of the 90 patients, $83(92.2 \%)$ had pulmonary tuberculosis (median lobes affected, 4), $6(6.7 \%)$ had pleural tuberculosis, and $12(13.3 \%)$ had extrapulmonary tuberculosis (some patients had more than one form of TB). Patients died a median of 5.5 days after entering the TB ward. The causes of death were: hemoptysis, 6 patients $(6.7 \%)$; other tuberculosis-related causes, 65 patients $(72.2 \%)$; drug reactions, 6 patients (6.7\%); nontuberculosis causes, 6 patients (6.7\%); and undetermined causes, 7 patients (7.8\%). Factors possibly contributing to death were late diagnosis (38.9\%), errors in follow-up (14.4\%), and errors in treatment (24.4\%). In conclusion, most patients with active or inactive TB admitted to our ward died as a consequence of tuberculosis. There were several factors possibly contributing to their fatal outcome that could be corrected.

Among the infectious diseases agents, Mycobacterium tuberculosis has been, until recently, the single biggest killer of mankind (1). More than two decades ago a leading expert thought the pathogen would soon cease to constitute a public health problem (2). Nevertheless, almost three million persons die annu-

\footnotetext{
Catalan Association for the Prevention and Treatment of Tuberculosis in the Third World (ACTMON), Barcelona, Spain. Send correspondence to: Jaime E. Ollé-Goig, Amigó 76, 08021 Barcelona, Spain; fax: 3493 2654311; e-mail: nicogallego@ retemail.es
}

ally from tuberculosis (TB), despite the existence of very effective antimicrobials that, when applied correctly, will cure almost all patients diagnosed early. TB accounts for more than one-fourth of the deaths around the world that could be prevented by applying existing technical and scientific knowledge (3). The combined infection by Mycobacterium tuberculosis and the human immunodeficiency virus (HIV) is proving deadly, and TB constitutes the main cause of death worldwide among patients with the acquired immunodeficiency syndrome (AIDS).
The estimated incidence of TB in Bolivia is one of the highest in the Americas (4), and in this country the region (department) of Santa Cruz notifies one of the highest TB detection rates and one of the lowest cure rates (5). Taking into consideration a World Health Organization study that estimated that in Bolivia in 1995 the annual case notification rate of all forms of TB was $129.67 / 100000$, and that this represented about $63 \%$ of the cases, we can calculate the number of TB cases in Bolivia at 15 260, given the country's population of 7414000 at that time (6). 
Assuming, conservatively, that $5 \%$ of the patients receiving treatment and $25 \%$ of those not diagnosed will die, then almost 2000 patients with TB die in Bolivia each year.

There have been some arguments about whether patients with TB nowadays die from the disease itself or from other causes $(7,8)$. In this study I attempted to analyze why patients admitted to a hospital's TB ward died, and to evaluate whether I could detect any factors that might contribute to their fatal outcome and that could have been prevented or corrected.
TABLE 1. Patients with tuberculosis hospitalized during the study period, by category and their case fatality, Santa Cruz, Bolivia, 1993-1996

\begin{tabular}{|c|c|c|c|c|}
\hline \multirow[b]{2}{*}{ Category } & \multicolumn{2}{|c|}{ Patients in category } & \multicolumn{2}{|c|}{$\begin{array}{c}\text { Patients in that category } \\
\text { who died }\end{array}$} \\
\hline & No. & $\%$ & No. & $\%$ \\
\hline Abandon & 133 & 22.3 & 23 & 17.3 \\
\hline Diagnostic error & 9 & 1.5 & 8 & 88.9 \\
\hline Sequelae & 64 & 10.7 & 6 & 9.4 \\
\hline New & 324 & 54.3 & $46^{\mathrm{a}}$ & 14.2 \\
\hline Resistant & 24 & 4.0 & 5 & 20.1 \\
\hline Under treatment & 31 & 5.2 & 6 & 19.3 \\
\hline Relapse & 12 & 2.0 & 0 & 0 \\
\hline Total & 597 & 100.0 & $94^{\mathrm{a}}$ & 15.7 \\
\hline
\end{tabular}

a The records of four of the new patients who died were not available at the time of analysis, so only 90 clinical records were reviewed and are reported on in Table 2.

\section{METHODS}

Patients were drawn from a crosssectional observational study described elsewhere (9). The study was conducted at the San Juan de Dios Hospital (SJDDH) in the city of Santa Cruz, in the Bolivian department of the same name, over the 29 months from October 1993 through February 1996. All the patients diagnosed with TB at SJDDH are routinely admitted for further evaluation and initiation of treatment. Anti-TB treatment is provided at no charge to the patient by the National Tuberculosis Control Program (NTCP). The therapeutic regimen in use during the study period was fully supervised and consisted of one month of daily isoniazid, rifampin, pyrazinamide, and streptomycin, followed by 6 months of isoniazid and rifampin administered twice a week.

We reviewed the available hospital records of the patients admitted for TB or for its sequelae. We examined demographic and clinical variables that included sex, age, residence, TB form, number of lobes affected, cause of death, and number of days hospitalized. The patients were categorized as follows:

- new: a patient never treated or having received anti-TB treatment for less than one month

- abandon: a new patient having interrupted the anti-TB treatment for more than one month
- diagnostic error: a patient suffering from TB and hospitalized with another diagnosis

- TB sequelae: a patient with a history of TB treated and cured, with symptoms attributed to the disease and no evidence of new TB infection

- resistant: a patient with known resistance to any anti-TB medication

- under treatment: a new patient on anti-TB treatment for more than one month

- relapse: a patient with a history of TB treated and cured and who returned with a positive sputum smear

We divided the causes of death into five categories:

- hemoptysis: a patient dying with a massive pulmonary hemorrhage

- other TB-related causes: a patient dying from any other cause that could be attributed to TB

- reaction to anti-TB medication: a patient suffering an adverse reaction to an anti-TB medication and dying from it

- non-TB cause: a patient dying from a condition unrelated to TB

- undetermined: a patient dying from a cause that could not be identified

We also examined whether there had been a delay in the diagnosis of TB (diagnosis of TB delayed more than one month after the patient attended a health facility for the first time) or an error in the follow-up or in treatment (evidence that any of the norms and guidelines of the NTCP's manual had not been followed without a specified and valid reason).

\section{RESULTS}

During the study period the TB ward admitted 597 patients with active TB or suffering from its sequelae, including 324 new patients, who represented almost $10 \%$ of the new patients diagnosed in the region of Santa Cruz during the 29-month period. Out of the 597 patients, 94 (15.7\%) died. Table 1 shows all the hospitalized patients listed by category and their case fatality rate. The five resistant patients who died were known to have multidrug-resistant TB (resistant to at least isoniazid and rifampin).

The records of four new patients out of the 94 were not available at the time of analysis, so we reviewed 90 clinical records, which are described in the sections that follow.

The 90 patients had a mean age of 35.1 years (median, 28 years; standard deviation (SD), 16.7 years). Males had a mean age of 38.7 years (median, 35; $\mathrm{SD}, 18.1)$, and females had a mean age of 31.5 years (median, 27; SD, 14.5). Out of the 90 , there were 45 males 
$(50.0 \%)$. In terms of residence, 62 of the patients $(68.9 \%)$ resided in the city of Santa Cruz, 17 (18.9\%) did not reside there, and for 11 of them $(12.2 \%)$ the residence could not be determined. Eighty-three patients $(92.2 \%)$ had pulmonary TB, $6(6.7 \%)$ had pleural TB, and $12(13.3 \%)$ had extrapulmonary TB (some patients had more than one form of TB). The mean number of lobes affected in all patients with pulmonary TB was 3.8 (median, 4; SD, 1.5); the mean and median number for each category were, respectively: abandon, 3.7 and 4; erroneous diagnosis, 4.2 and 5; sequelae, 2.4 and 2; new, 3.9 and 5; resistant, 4.0 and 5; and under treatment, 3.0 and 2. Seventeen patients $(18.9 \%)$ presented an associated medical condition, such as diabetes, hypertension, or renal failure.

Patients died a mean of 18.5 days after entering the TB ward (median, 5.5 days; range: $1-490$ days; SD, 53.6 days). Within the first day after admission $20 \%$ of the patients had died, $30 \%$ had died within 2 days, and $50 \%$ had died by day 5 after admission.

The causes of death for the various categories of patients are listed in Table 2. Of the six patients dying from hemoptysis, five presented hemoptysis on admission. For the 65 patients dying from other TB-related causes, the specific causes were: respiratory insufficiency, 31 patients $(34.4 \%)$; a combination of widespread infection, anemia, cachexia, and sudden unexplained death (10), 24 patients (26.7\%); meningitis/central nervous system tuberculoma, 5 patients (5.6\%); cor pul- monale, 3 patients $(3.3 \%)$; Addison's disease, 1 patient $(1.1 \%)$; and pericardial tamponade, 1 patient $(1.1 \%)$. Of the 6 patients dying from a non-TB cause, 5 had an associated condition on admission; the other patient developed an acute abdomen while in the hospital.

The diagnosis of TB was delayed in 35 patients (38.9\% of the 90$)$, and there were errors in the follow-up of 13 patients $(14.4 \%)$ and in the treatment of 22 patients $(24.4 \%)$.

\section{DISCUSSION}

Our study shows that the majority of the patients with active or inactive TB who died in the TB ward of the main public hospital in Santa Cruz, Bolivia, died from the disease itself or its sequelae: 71 patients $(78.9 \%$ of the 90$)$ died from causes related to TB. If we add to them the 6 patients who died from an adverse treatment reaction, then 77 patients $(85.5 \%)$ died, directly or indirectly, due to TB. In 72 of those $77(93.5 \%)$ the disease was active.

A review of 41 patients dying with active TB in the United States of America in the pre-AIDS era found that more than half of them died of coexisting medical problems unrelated to $\mathrm{TB}$ (11). However, patients dying with TB in a developed country with a low incidence of the disease constitute a different population from ours in Bolivia. This is shown, for example, by the predominance of males $(82.9 \%)$ in that United States study, as well as the fact that the patients were older (mean age, 59 years) in the United States study than in our Bolivian study.

One might conclude that our TB facility in Santa Cruz constituted a referral center and therefore was the recipient mostly of difficult cases (this might explain the large proportions of patients with adverse reactions to treatment and with multidrug-resistant TB). However, the problem was probably elsewhere. This is suggested by the fact that among the 46 new patients who died, the diagnosis was delayed in 28 of them $(60.1 \%)$, including 19 persons who lived in the city of Santa Cruz. The severity of the disease upon admission was an indication of diagnostic delay and was shown by the number of lobes affected and the high proportion of patients who died shortly after admission.

Delayed diagnoses have been found in other studies on the cause of death of TB patients. A long delay in diagnosis was identified in $36.7 \%$ of the patients in an English hospital necropsy study (10). A large autopsy review of patients who died from TB in a Yugoslavian hospital for lung diseases found that late detection of TB was the main contributor to the TB fatalities (12). A study from New York City looking at newly diagnosed TB cases found that over the following 42 months, most HIV-infected patients whose anti-TB treatment was delayed died (13). A study conducted in Johannesburg, South Africa, an area with a high prevalence of HIV infection, also suggested that late diagnosis was associ-

TABLE 2. Status of 90 tuberculosis patients who died during hospitalization, and their cause of death, Santa Cruz, Bolivia, 1993-1996

\begin{tabular}{lcccccc}
\hline \multicolumn{1}{c}{ Status } & Hemoptysis & $\begin{array}{c}\text { Other TB-related } \\
\text { cause }\end{array}$ & Drug reaction & Non-TB cause & Undetermined & Total \\
\hline Abandon & 1 & 19 & 0 & 2 & 1 & 23 \\
Diagnostic error & 0 & 8 & 0 & 0 & 0 & 8 \\
Sequelae & 1 & 4 & 0 & 1 & 0 & 6 \\
New & 2 & 29 & 2 & 3 & 6 & 42 \\
Resistant & 2 & 3 & 0 & 0 & 0 & 5 \\
Under treatment & 0 & 2 & 4 & 6 & 0 & 7 \\
$\quad$ Total & 6 & 65 & 6 & 0 & 90 \\
\hline
\end{tabular}


ated with in-hospital death of patients with active TB (14).

The purpose of our study in Bolivia was not to investigate delays in diagnosis, either due to the patient or the health system. Nevertheless, our findings indicate that conducting operational studies to quantify such delay and find its causes should be a priority for the NTCP and the local health authorities.

A delayed diagnosis was not the only problem that our patients encountered. After TB was identified, a significant proportion of patients were not followed up correctly, did not receive adequate treatment, or both. These factors may also have contributed to the deaths among the population we studied. A survey conducted in the city of Santa Cruz suggested that prescribing incorrect anti-TB treatments was not infrequent among private physicians (15). Medical practice that ignores appropriate treatment norms may have dire consequences for patients and the community (16).
It may seem paradoxical, with such effective antimicrobials currently available, that TB deaths continue to occur and are such a source of suffering, especially in developing countries (17). But this situation may be perceived differently when we realize that to be cured, a patient must be promptly diagnosed and prescribed the correct treatment. Provided that the medications are available, then and only then will the patient have the opportunity to ingest-at the correct doses and intervals-several hundred tablets (and in some cases receive no fewer than two dozen intramuscular injections) to be rid of the infecting bacilli. Clearly, the road to recovery for a TB patient is long, tortuous, and not without multiple obstacles (18). Our aim should be to make that road as smooth and short as possible, so as to ensure a full recovery for patients and a prompt interruption of the spread of infection.

To achieve these goals in Bolivia we suggest that several measures are urgently needed, including campaigns to

\section{REFERENCES}

1. Kochi A. The global tuberculosis situation and the new control strategy of the World Health Organization. Tubercle 1991;72:1-6.

2. Edwards PQ. Is tuberculosis still a problem? Health Serv Rep 1973;88(6):483-486.

3. Bloom BR, Murray CJL. Tuberculosis: commentary on a reemergent killer. Science 1992; 257(5073):1055-1063.

4. Organización Panamericana de la Salud. El control de la tuberculosis en las Américas. Bol Epidemiol 1998;19(2):1-8.

5. Programa Nacional de Vigilancia y Control de la Tuberculosis. Informe 1996. La Paz, Bolivia: Secretaría Nacional de Salud; 1997.

6. The WHO/IUATLD Global Project on Antituberculosis Drug Resistance Surveillance. Anti-tuberculosis drug resistance in the world. Geneva: World Health Organization; 1997.

7. Enarson DA. Failure of diagnosis: a key indicator in quality assurance of tuberculosis control. Tuber Lung Dis 1995;76(4):279-280.

8. Ollé-Goig JE. Failure of diagnosis: a key indicator in quality assurance of tuberculosis control. Tuber Lung Dis 1996;77(2):193-194.

9. Ollé Goig JE, de la Puente ML. Estudio de los enfermos ingresados en una sala de tubercu- losis de un hospital en Santa Cruz. Carta Médica AIS 1998;13:14-18.

10. Ellis ME, Webb AK. Cause of death in patients admitted to hospital for pulmonary tubercu-

11. Davis CE, Carpenter JL, McAllister K, Matthews J, Bush BA, Ognibene AJ. Tuberculosis. Cause of death in antibiotic era. Chest 1985;88(5):726-729.

12. Zafran N, Heldal E, Pavlovic S, Vuckovic D, Boc J. Why do our patients die of active tuberculosis in the era of effective therapy? Tuber Lung Dis 1994;75(5):329-333.

13. Pablos-Méndez A, Sterling TR, Frieden TR. The relationship between delayed or incomplete treatment and all-cause mortality in patients with tuberculosis. JAMA 1996;276(15): 1223-1228.

14. Sacks LV, Pendle S. Factors related to in-hospital deaths in patients with tuberculosis. Arch Intern Med 1998;158(17):1916-1922.

15. Olle-Goig JE, Cullity JE, Vargas R. A survey of prescribing patterns for tuberculosis treatment amongst doctors in a Bolivian city. Int J Tuberc Lung Dis 1999;3(1):74-78.

16. Datta M, Radhamani MP, Selvaraj R, Paramasivan CN, Gopalan BN, Sudeendra CR, et al. losis. Lancet 1983;1(8326 Pt 1):665-667. educate the population; training and supervision of health personnel; periodic reviews of the SJDDH's clinical records, laboratory registers, and radiographs; and a system of incentives to reward the adoption of the norms and procedures of the NTCP's manual.

Several years ago Zafran et al. (12) posed the question, "Why do our patients die of active TB in the era of effective therapy?" Unless we take appropriate steps, we risk having to give again the same response that they did: "Because we are not able to detect them in time and because we are unable to treat them correctly." Without suitable action, two-thirds of the world's population will continue to have no access to adequate TB care (19).

Acknowledgments. I would like to thank all the people I worked with at the Hospital San Juan de Dios, Santa Cruz, Bolivia, while I was serving as the Representative in Bolivia of the German Leprosy Relief Association.
Critical assessment of smear-positive pulmonary tuberculosis patients after chemotherapy under the district tuberculosis programme. Tuber Lung Dis 1993;74(3):180-186.

17. Murray CJL, Styblo K, Rouillon A. Tuberculosis in developing countries: burden, intervention and cost. Bull Int Union Tuberc Lung Dis 1990;65(1):2-20.

18. Dujardin B, Kegels G, Buvé A, Mercenier P. Tuberculosis control: did the programme fail or did we fail the programme? Trop Med Int Health 1997;2(8):715-718.

19. Becx-Bleumink M, Broekmans JF. Tuberculosis: where do we stand? Trop Med Int Health 1998;3(6):423-424.

Manuscript received on 17 November 1999. Revised version accepted for publication on 3 April 2000 
RESUMEN El objetivo de esta investigación consistió en determinar por qué mueren los pacientes con tuberculosis (TBC) y si existen factores que contribuyen al desenlace fatal que puedan ser modificados. Durante un período de 29 meses, de octubre de 1993 a febrero de 1996, se realizó un estudio observacional transversal de los pacientes con TBC activa o secuelas ingresados en la planta de TBC del principal hospital público de la ciudad de Santa Cruz, Bolivia. Se revisaron los registros hospitalarios de los pacientes que fallecieron durante la hospitalización. Fallecieron 94 de 597 pacientes $(15,7 \%)$ y se revisaron los registros hospitalarios de 90 de ellos. El promedio de edad fue de 35,1 años (desviación estándar de 16,7) y 45 pacientes (50\%) eran varones. En el momento del ingreso, 42 de los 90 pacientes (46,7\%) nunca habían recibido tratamiento antituberculoso, o bien solo lo habían recibido durante menos de un mes; 23 $(25,6 \%)$ habían vuelto al hospital después de haber abandonado el tratamiento; 8 $(8,9 \%)$ habían recibido un diagnóstico equivocado; 6 (6,7\%) tenían secuelas de TBC; otros 6 estaban recibiendo tratamiento antituberculoso, y $5(5,6 \%)$ padecían TBC resistente a múltiples fármacos. De los 90 pacientes, $83(92,2 \%)$ tenían TBC pulmonar (mediana de lóbulos afectados: 4); 6 (6,7\%) TBC pleural, y 12 (13,3\%) TBC extrapulmonar (algunos pacientes presentaban más de una forma de TBC). El número mediano de días transcurridos entre el ingreso en la planta de TBC y el fallecimiento fue de 5,5. Las causas de muerte consistieron en: hemoptisis en 6 casos (6,7\%); otras causas relacionadas con la TBC en $65(72,2 \%)$; reacciones a fármacos en 6 ; causas no relacionadas con la TBC en otros 6 , y causas indeterminadas en 7 (7,8\%). Los factores que posiblemente contribuyeron a la muerte fueron el diagnóstico tardío $(38,9 \%)$, los errores en la vigilancia del caso $(14,4 \%)$ y los errores en el tratamiento $(24,4 \%)$. En resumen, la mayoría de los pacientes con TBC activa o inactiva ingresados en nuestra planta fallecieron a consecuencia de la TBC. Hubo varios factores potencialmente corregibles que posiblemente contribuyeron al resultado mortal. 